\title{
Chiral selection in the formation of borates from racemic binaphthols and related diols $\dagger$
}

\author{
Jevgenij A. Raskatov, ${ }^{a b}$ John M. Brown ${ }^{a}$ and Amber L. Thompson*c \\ Received 8th October 2010, Accepted 20th January 2011 \\ DOI: 10.1039/c0ce00709a
}

\begin{abstract}
A series of racemic or stereochemically labile chiral borate anions based on the 2,2'-biphenol motif was investigated. All borates were homochiral in the solid state, although in some cases the heterochiral diastereomers were computed to be thermodynamically preferred (DFT). The crystallographic preference for the homochiral diastereomer was attributed to its lower bulk, higher molecular symmetry, and the therewith associated better packing ability.
\end{abstract}

\section{Introduction}

Chiral counterions have received increasing attention from the asymmetric catalysis community over the past few years. ${ }^{1}$ BINOL is the foremost example of axial chirality. The chiral backbone of BINOL is stereochemically stable (atropos) and the enantiomers can be readily resolved; ${ }^{2}$ it has been one of the most extensively used motifs in the creation of chiral anions (Fig. 1). Some spectacular applications of BINOL-based chiral phosphates $\mathbf{1}$ in asymmetric catalysis have recently been demonstrated. $^{3}$ The bis-BINOL borate $\mathbf{2}$, initially introduced by Periasamy for the purpose of resolving amino alcohol derivatives, ${ }^{4}$ has been studied less extensively in the asymmetric catalysis context. ${ }^{5}$

The synthesis of bis-BINOL borates from racemic BINOL can yield the homochiral $(R, R)_{\mathrm{ax}}$ and $(S, S)_{\mathrm{ax}}$ or the heterochiral $(R, S)_{\text {ax }}$ diastereomers. Recent studies of bis-BINOL 2 or biphenol 3 borates by Wuest and co-workers have demonstrated that both form homochiral anions upon crystallisation from a racemic solution in the presence of various amines as well as other counterions. ${ }^{6}$ The bis-biphenol borate anion (3) framework is stereochemically labile (tropos) and the stereoselection is therefore limited to the solid state (vide infra).

As part of a project designed to study chiral ion pairs of relevance to asymmetric catalysis, ${ }^{7}$ homochiral racemates of various substituted bis-BINOL borates with sodium as counterion were required. Herein we report the results of our systematic investigation.

${ }^{a}$ Department of Chemistry, Chemistry Research Laboratory, 12 Mansfield Road, OX1 3TA Oxford, UK

${ }^{b}$ California Institute of Technology, 1200 E California Blvd, Pasadena, CA, 91125,USA.E-mail: raskatov@caltech.edu

${ }^{c}$ Chemical Crystallography, Chemistry Research Laboratory, 12 Mansfield Road,OX13TA Oxford, UK.E-mail: amber.thompson@chem.ox.ac.uk $\uparrow$ Electronic supplementary information (ESI) available: Structural data for each crystal structure reported in CIF format. CCDC reference numbers 796350-796357. For ESI and crystallographic data in CIF or other electronic format see DOI: 10.1039/c0ce00709a

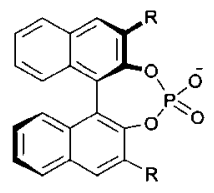

1

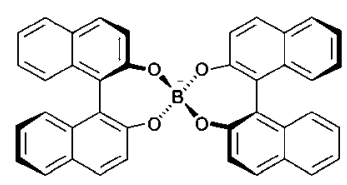

2

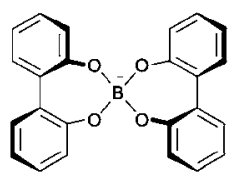

3
Fig. 1 BINOL phosphate 1, bis-BINOL borate 2, and bis-biphenol borate 3 anions, all shown as $(R)_{\mathrm{ax}}$ isomers.

\section{Results and discussions}

\section{Configurationally stable borates}

When two equivalents of racemic BINOL were subjected to the condensation reaction with $\mathrm{NaB}(\mathrm{OMe})_{4}$, a single compound was obtained. A series of NMR experiments identified it as the

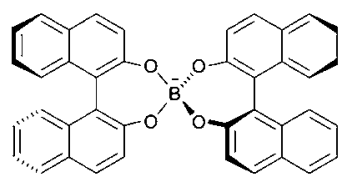

rac-2

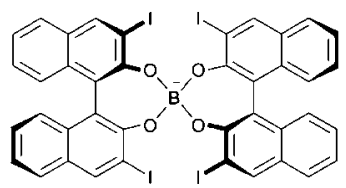

$\left(R_{a x}, R_{a x}\right)-5$

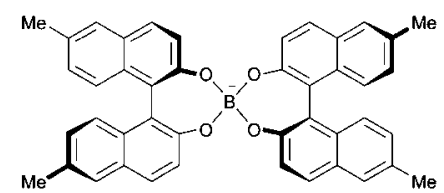

$$
\left(R_{a x}, R_{a x}\right)-4
$$

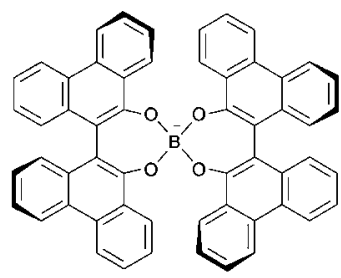

$\left(R_{\mathrm{ax}} R_{\mathrm{ax}}\right)-6$
Fig. 2 Configurationally stable or atropos borates discussed in the text above; the $(R)$-configuration of $\mathbf{4 - 6}$ is shown. 


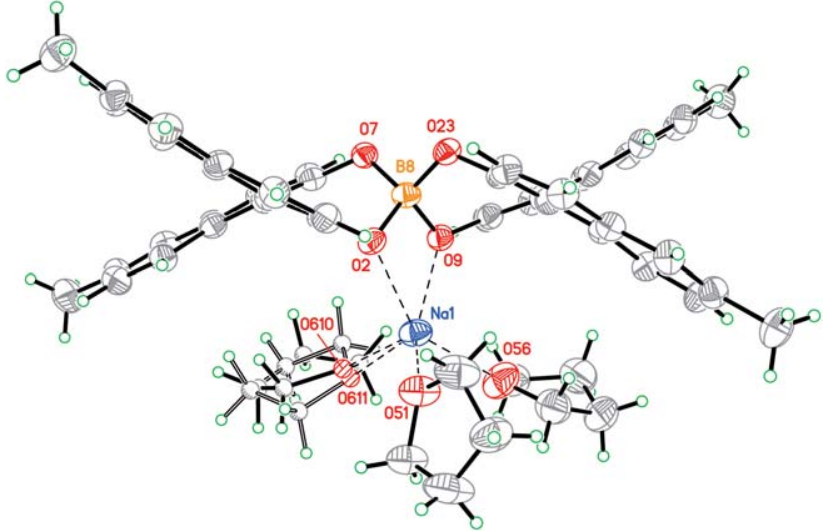

Fig. 3 Thermal ellipsoid plot of the crystal structure of $\mathbf{4}$ drawn at 30\% probability (for clarity).

racemate of the bis-binaphtholborate sodium salt $\mathbf{2}$, each anion being homochiral. ${ }^{8}$ The yield of the compound was higher than $90 \%$, demonstrating diastereoselection in favour of the homochiral species $\left(R^{*}{ }_{\mathrm{ax}}, R^{*}{ }_{\mathrm{ax}}\right)-2$ over the heterochiral species $\left(R_{\mathrm{ax}},-\right.$ $\left.S_{\mathrm{ax}}\right)$-2. ${ }^{9}$ An analogous result was obtained starting from racemic 6,6'-dimethyl BINOL, yielding the bis-6,6'-dimethyl-BINOLborate sodium salt $\mathbf{4}$ (Fig. 2). The crystal structure of $\mathbf{4}$ is shown in Fig. 3.

An attempt was made to rationalise the diastereoselection by conducting DFT calculations on the homochiral and the heterochiral bis-BINOL-borate anions. However, at the isolated anion level, an essentially negligible thermodynamic differentiation $\left(0.4 \mathrm{kcal} \mathrm{mol}^{-1}\right.$ in favour of the heterochiral diastereomer) was computed. A striking difference in shape was observed between the two, the homochiral entity being "disk-shaped" while the heterochiral species was considerably more bulky (Fig. 4). Examination of this suggested that an increase in the

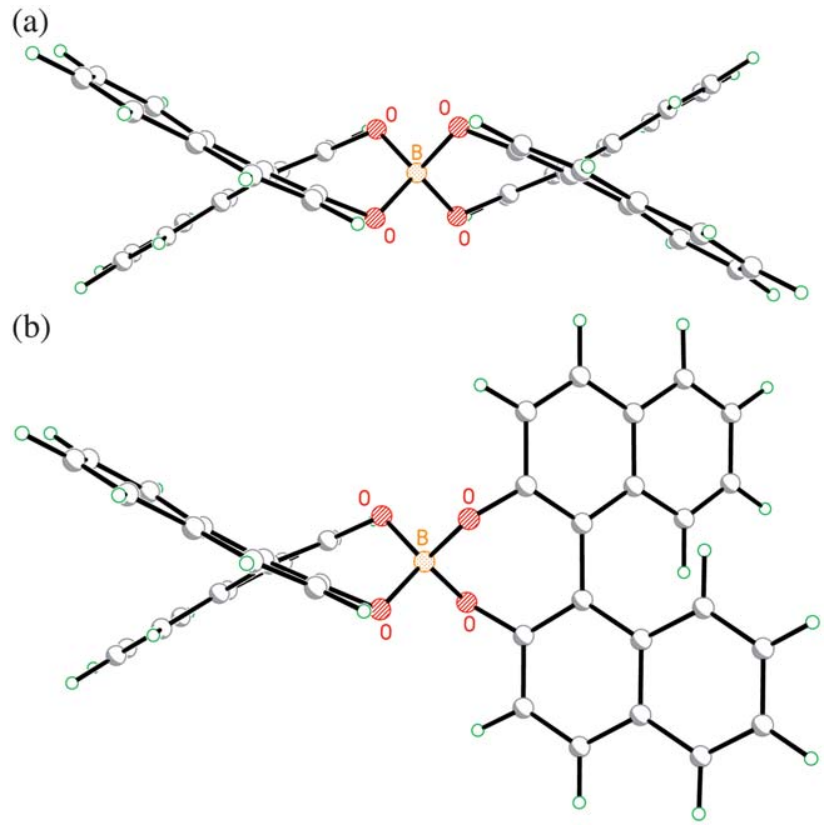

Fig. 4 Minimum energy structures of the diastereomers of 2 from DFT; homochiral $\left(R_{\mathrm{ax}}, R_{\mathrm{ax}}\right)$-2 (a) and heterochiral $\left(R_{\mathrm{ax}}, S_{\mathrm{ax}}\right)$-2 (b). Coordinates are included in the SI (CIF) for $3 \mathrm{D}$ visualisation

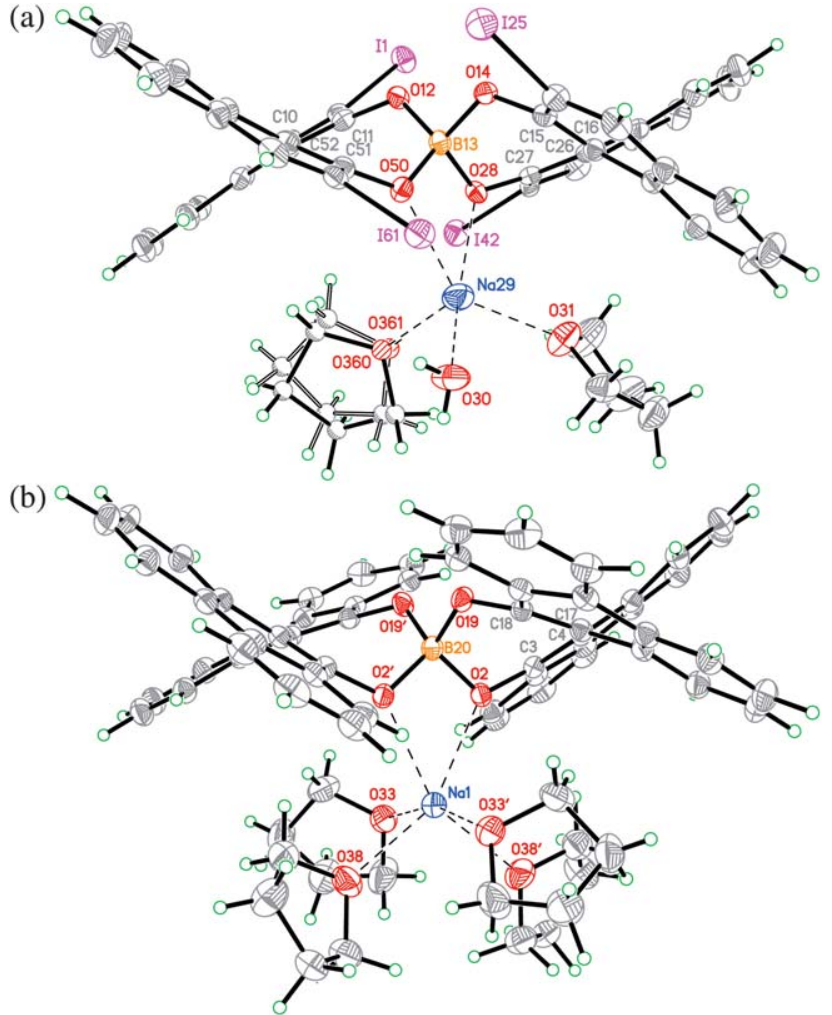

Fig. 5 Thermal ellipsoid plots of the structures of 5 (a) and $\mathbf{6}$ (b) drawn at $50 \%$ probability. Selected bond lengths for 5 [^]: B13-O12: 1.460(5), B13-O14: 1.469(5), B13-O28: 1.481(5), B13-O50: 1.481(5), Na29-O28: 2.308(3), Na29-O30: 2.233(3), Na29-O31: 2.371(3), Na29-O50: 2.524(3), Na29-O360: 2.268(7), Na29-O361: 2.337(7). Selected angles for $5\left[^{\circ}\right]$ : O12-B13-O14: 100.6(3), O12-B13-O28: 114.7(3), O12-B13-O50: 114.7(3), O12-B13-O50: 114.7(3), O14-B13-O28: 113.0(3), O14-B13O50: 114.7(3), O28-B13-O50: 99.8(3). Selected dihedral angles for $5\left[^{\circ}\right]$ : C11-C10-C52-C51: -54.4(5), C15-C16-C28-C27: -53.5(5). Selected bond lengths for $6[\AA]$ : B20-O2: 1.4783(17), B20-O19: 1.4636(17), Na1O2: 2.4737(12), Na1-O33: 2.4463(11), Na1-O38: 2.3615(12). Selected angles for $6\left[^{\circ}\right]$ : O2-B20-O19: 113.03(5), O2-Na1-O2': 100.47(15), O2B20-O19': 114.69(5), O19-Na1-O19': 101.56(16). Selected dihedral angle [ ${ }^{\circ}$; C3-C4-C17-C18: -48.7(2).

steric bulk at the 3,3'-positions in BINOL should lead to preferential formation of the heterochiral entity.

A suitable series of DFT calculations identified 3, $3^{\prime}$-diiodo2,2'-binaphthol and 9,9'-biphenanthrol as viable precursors with a substantial thermodynamic preference for the heterochiral anion (4.9 and $3.2 \mathrm{kcal} \mathrm{mol}^{-1}$, respectively). The sodium salts of bis-3,3'-diiodobinaphtholborate 5 and bis-9,9'-biphenanthrolborate $\mathbf{6}$ ( $c f$. Fig. 2) were prepared following the standard condensation method with $\mathrm{NaB}(\mathrm{OMe})_{4}$. Single crystals were obtained for both compounds, but in conflict with the DFT prediction, both $\mathbf{5}$ and $\mathbf{6}$ were found to be homochiral (Fig. 5). A single crystal ${ }^{1} \mathrm{H}$ NMR experiment was conducted for 6 and confirmed that the homochiral crystal indeed corresponded to the bulk material (Fig. 6). It was thought that this could be an effect due to the influence of the sodium counterion. In all crystal structures discussed so far, the cation exhibited short contacts with two oxygen atoms of the respective anion. It was thought that a similar binding mode for the heterochiral borates would be sterically less accessible 


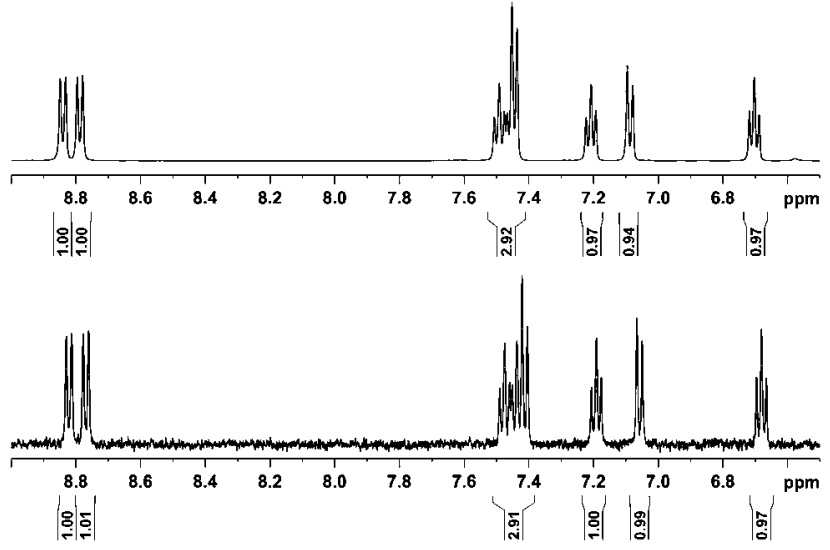

Fig. 6 NMR derived from the bulk material (top) and from the crystalline sample used in structure determination (bottom) of (6).

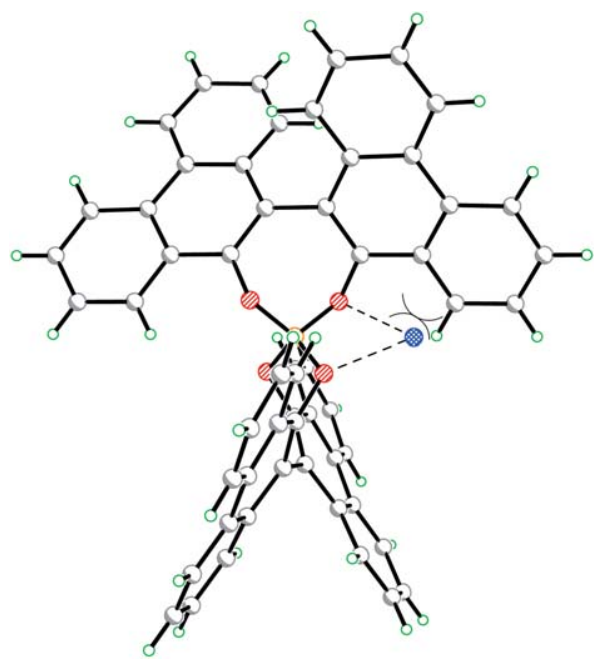

Fig. 7 DFT model of a heterochiral version of $\mathbf{6}$ with the sodium atom geometrically added to demonstrate the steric hindrance.

due to the substantial difference in shape between the homoand the heterochiral anions (Fig. 7). This question was addressed by preparing a stereochemically labile borate analogue and studying its 18,6-crown ether complex.

\section{Configurationally labile borates}

The tropos-biphenyl analogue of 5 was made from 3,3'-diiodo2,2'-biphenyl, yielding bis-3, $3^{\prime}$-diiodo-2,2'-biphenylborate 7 (Fig. 8).

A DFT computational analysis of the diastereoisomers of anion 7 carrying bulky iodide residues at all four 3 - and $3^{\prime}$ -<smiles>Ic1cccc(I)c1OP12(Oc3cccc(I)c3O1)Oc1c(I)cccc1-c1cccc(I)c1O2</smiles>

7

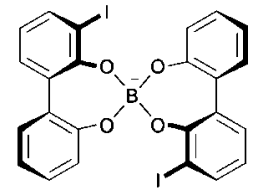

8

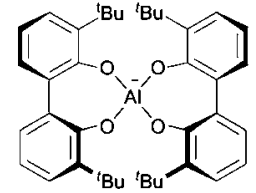

9
Fig. 8 Tropos Borates 7 and $\mathbf{8}$, drawn as homochiral $(R, R)_{\mathrm{ax}}$ isomers, and the heterochiral aluminate 9 . (a)

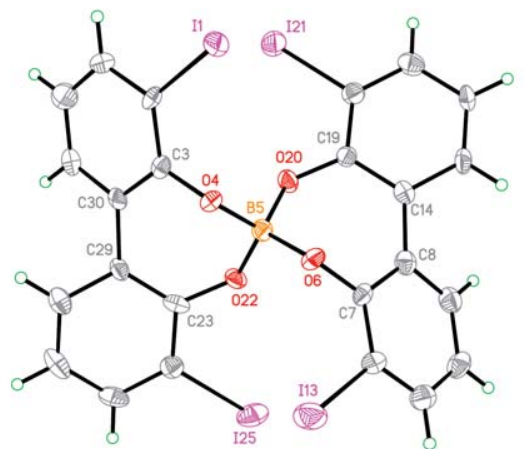

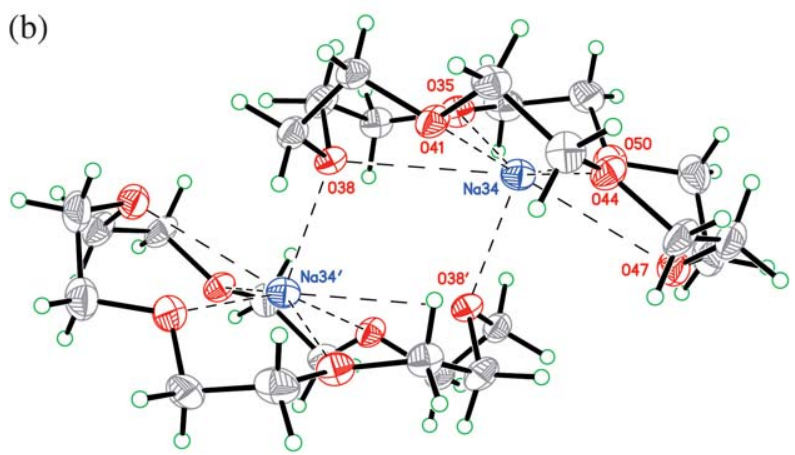

Fig. 9 Thermal ellipsoid plot of the anion of 7 (a); showing the Na cation complexed by 18,6-crown ether (b) with the thermal ellipsoids drawn at 50\% probability. Selected bond lengths [A]: B5-O4: 1.467(5), B5-O6: 1.459(5), B5-O20: 1.481(6), B5-O22: 1.470(5). Significant angles [']: O4-B5-O22: 113.4(3), O6-B5-O20: 113.7(3), O4-B5-O6: 103.6(3), O4-B5-O20: 111.1(3), O6-B5-O22: 111.8(3), O20-B5-O22: 103.5(3). Selected dihedral angles [ ${ }^{\circ}$ ]: C23-C29-C30-C3: -41.1(3), C7-C8-C14C19: -43.1(6).

positions predicted a thermodynamic preference for the heterochiral anion by $4.2 \mathrm{kcal} \mathrm{mol}^{-1}$. The origin of this is straightforward; in the $D_{2}$-symmetric form of the homochiral anion close I-I interactions are observed unless the borate rings adjust by flattening. Importantly, the interconversion barrier between the homo- and heterochiral anion was calculated to be as low as 7.9 $\mathrm{kcal} \mathrm{mol}^{-1}$, thus validating the assumption of stereochemical lability at ambient temperature. Correspondingly only one signal set was seen in solution ${ }^{1} \mathrm{H}$ NMR even at temperatures as low as $188 \mathrm{~K}\left(\mathrm{CD}_{2} \mathrm{Cl}_{2}\right.$; the crown complex of $\mathbf{5}$ was used to improve the
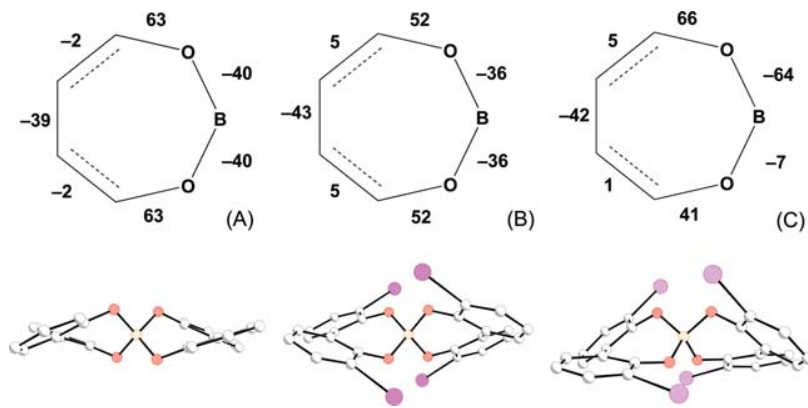

Fig. 10 Dihedral angles for $(R)$-borate rings are shown with the corresponding structures: the unstrained conformation seen in the majority of structures described here and in the literature as demonstrated by $3 \mathbf{c}(\mathrm{A})$; distortion induced in the $D_{2}$ conformation of anion $(R, R)-7$ from DFT (B), and the experimentally observed anion ring conformation from the $\mathrm{X}$-ray structure of $7(\mathrm{C})$. 


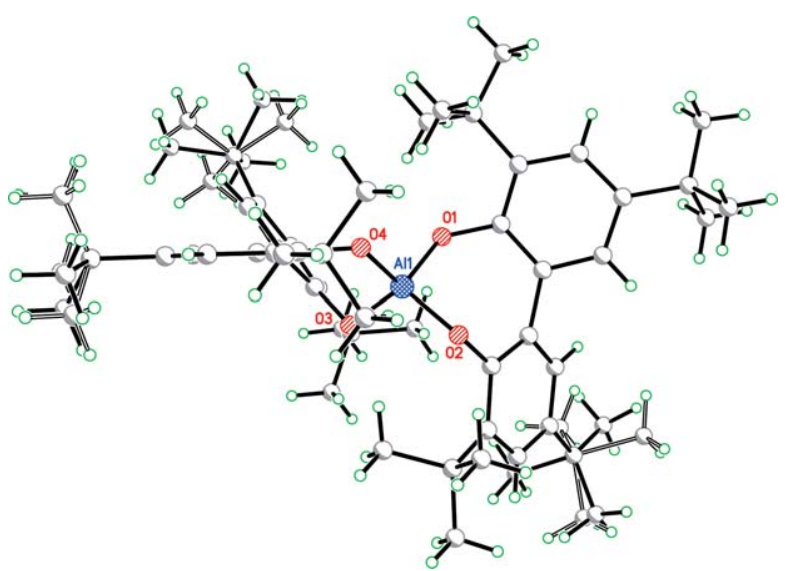

Fig. 11 The structure of the heterochiral 3,3'-bis-tert-butyl-2,2'-biphenol aluminate anion 9 reported by Straub et al. demonstrating the orthogonality of the biphenyl groups.

compound solubility). Despite the prediction arising from the DFT calculations, the crystal structure of the 18,6-crown $\mathrm{Na}^{+}$ complex of 7 was found to be homochiral (Fig. 9), but each chelate ring had undergone significant conformational change such that the isolated anion is significantly distorted away from the original $D_{2}$ symmetry to $C_{2}$. The adjacent charged counterion, a dimeric sodium-crown ether pair, may well contribute to stabilising the alternative form. The alternative ring conformation that is seen only in anion 7 is shown in Fig. 10, alongside the more commonly observed form.

Thus further increase in the steric bulk could lead to the formation of heterochiral species. This theory is supported by the recently reported structure of a chiral aluminate 9 possessing $S_{4^{-}}$ symmetry, derived from 3,3'-di-tert-butyl biphenol (Fig. 11). This demonstrates nicely that heterochiral frameworks can indeed be obtained with very bulky $3,3^{\prime}$ substituents; the relative stability of the diastereomeric anions studied was also discussed. ${ }^{10}$

\section{Conglomerate or racemate?}

All compounds discussed hitherto were found to crystallise in centrosymmetric space groups. The tropos-analogue bis-biphenol borate 3 (Fig. 1) was also prepared and was crystallised as both the sodium salt (from THF and from diethyl ether, 3a and 3b respectively, Fig. 12) and the derived 18,6-crown ether complex (3c, Fig. 13). All three formed homochiral species that were found to crystallise in centrosymmetric space groups like those discussed previously.

Conglomerate formation, however, was observed with the bis3-iodo-2,2'-biphenol borate 8 (Fig. 8 and Fig. 15). Initially it was unclear why this occurred. A search for the bis-biphenol framework was conducted in the Cambridge Structural Database, specifying the $3,3^{\prime}$-substituent and the central atom as the search variables of the ligand (Fig. 14).

Eleven borates were identified, all containing two unsubstituted biphenol moieties. Therefrom, seven had achiral ammonium counterions (MITTEP, MITTIT, MITTOZ, MITTUF, MITVAN, MITVER, MITVIV), one had a phosphonium counterion (MITVOB) and two had chiral ammonium countercations (MITVUH and its corresponding racemate MITFUW) ${ }^{6}$ (a)
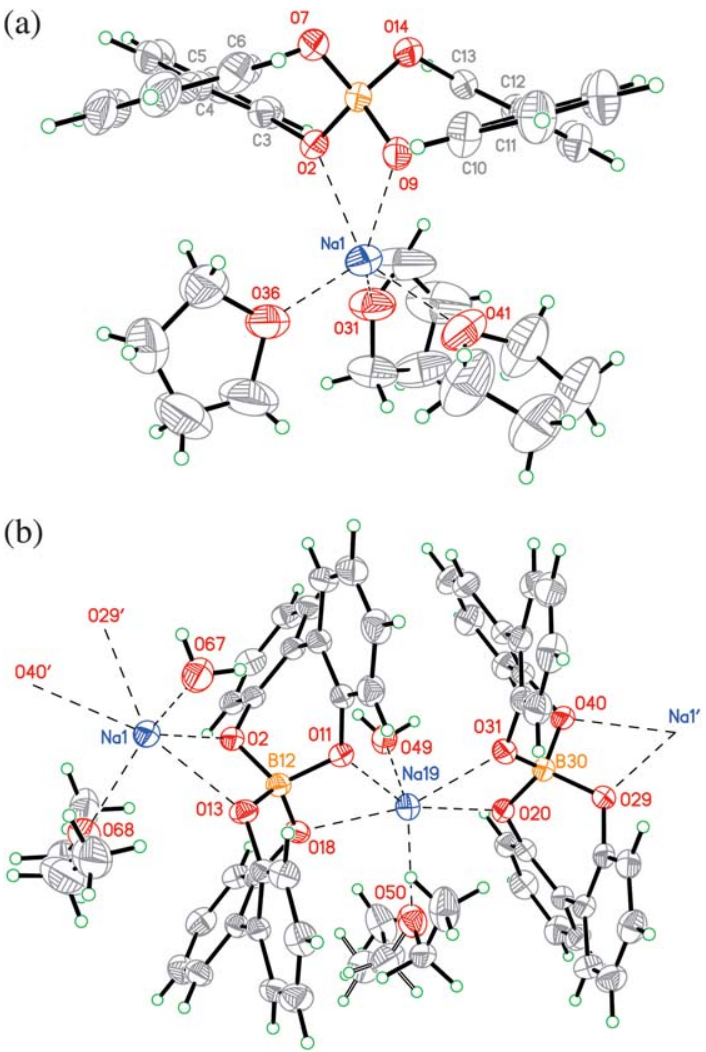

Fig. 12 Thermal ellipsoid plot of bis-biphenol borate, 3, as the sodium salt (a), crystallised from THF 3a and (b), as a 1D-polymeric chain crystallised from $\mathrm{Et}_{2} \mathrm{O}$, 3b. Selected bond lengths for 3a $[\AA]$ : $\mathrm{B} 8-\mathrm{O} 2$ : 1.480(4), B8-O7: 1.447(4), B8-O9: 1.477(4), B8-O14: 1.452(4), Na1-O2: 2.413(2), Na1-O9: 2.280(2), Na1-O31: 2.290(3), Na1-O36: 2.269(3), $\mathrm{Na} 1-\mathrm{O} 41: 2.328(3)$. Selected angles for 3a [ $\left.{ }^{\circ}\right]$ : O2-B8-O7: 112.8(2), O2B8-O9: 100.7(2), O2-B8-O14:113.0(2), O7-B8-O9: 112.6(2), O7-B8O14: 105.2(2), O9-B8-O14: 112.7(2). Selected dihedral angles for $\mathbf{3 a}\left[^{\circ}\right]$ : C3-C4-C5-C6: 42.8(4), C10-C11-C12-C13: 43.3(5). Representative bond lengths for 3b $[\AA]$ : B12-O2: 1.473(3), B12-O11: 1.472(3), B12-O13: 1.460(3), B12-O18: 1.456(3), Na1-O2: 2.4148(17), Na1-O13: 2.5095(17), Na1-O29': 2.4281(17), Na1-O40': 2.4866(18), Na1-O67: 2.374(2), Na1O68: 2.392(2). Representative angles for $3 \mathbf{b}\left[{ }^{\circ}\right]$ : O2-B12-O11: 112.32(18), O2-B12-O13: 101.60(17), O2-B12-O18: 114.02(19), O11-B12-O13: 113.92(19), O11-B12-O18: 101.47(17), O13-B12-O18: 113.94(18). Representative dihedral angles for $3 \mathbf{b}\left[{ }^{\circ}\right]$ : $\mathrm{C} 3-\mathrm{C} 4-\mathrm{C} 5-\mathrm{C} 10$ : 43.0(3), $\mathrm{C} 14$ C15-C16-C17: 39.5(3).

whereas one had a lithium cation, coordinated to the borate oxygens. ${ }^{11}$ In all these structures the borate moiety was homochiral. No evidence was available that any of the above underwent a spontaneous resolution upon crystallisation. The only borate case where a non-centrosymmetric space group was determined is the $(S)$ - $\alpha$-methylbenzylammonium cation (MITVUH; P2), whereas the corresponding $( \pm)$ - $\alpha$-methylbenzylammonium salt possessed a centrosymmetric lattice (MITFUW, $P 2 / n$ ). In addition to MITVUH, an unusual "tied" gallium species, KEZQAH, ${ }^{12}$ was also found featuring a dimethyl ether bridge from $\mathrm{X} 1$ to $\mathrm{X} 3$. This was found to crystallise in $P 2_{1}$, however, it was reportedly synthesised from enantiopure BINAP, so no further inference can be drawn.

On consideration of the structure of $\mathbf{8}$, there were some indications as to what made it unusual. Like $\mathbf{3 b}$, compound $\mathbf{8}$ crystallised as a 1D-polymeric chain containing both $R R$ - and 
(a)

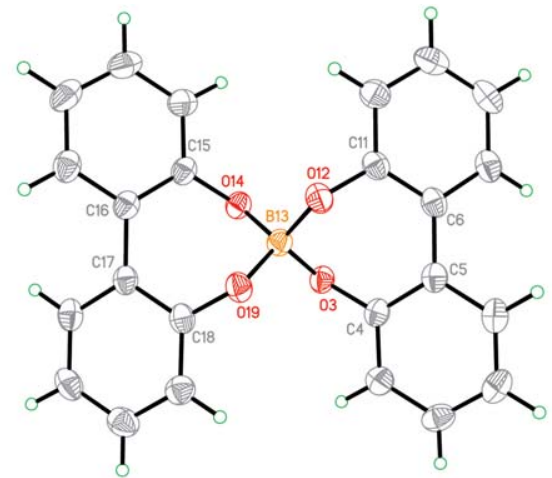

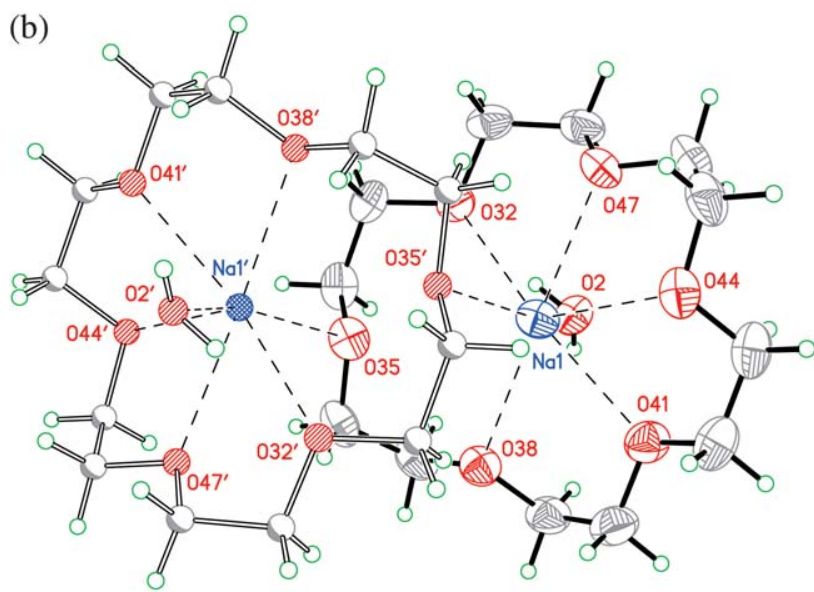

Fig. 13 Compound 3c, anion (a); and showing cation complexation (b) Selected bond lengths $[\AA]$ ]: B13-O3: 1.472(2), O12-B13: 1.457(3), B13O14: 1.472(3), B13-O19: 1.461(2). Selected angles [ ${ }^{\circ}$ ]: O3-B13-O12: 112.76(15), O3-B13-O14: 101.95(15), O3-B13-O19: 112.93(16), O12B13-O14: 113.37(16), O12-B13-O19: 103.20(15), O14-B13-O19: 113.02(15). Selected dihedral angles [ ${ }^{\circ}$ ]: $\mathrm{C} 4-\mathrm{C} 5-\mathrm{C} 6-\mathrm{C} 11: 41.1(3), \mathrm{C} 15-$ C16-C17-C18: 44.1(3).

SS-homochiral borates in the asymmetric unit (Fig. 15). The presence of both hands in the asymmetric unit of a Sohnke $e^{13}$ space group effectively made $\mathbf{8}$ a rare example of a chiral racemate. ${ }^{14}$ This unusual behaviour presumably arose because, in contrast to $\mathbf{3 b}$, the chains in $\mathbf{8}$ were distinctly helical in nature and in this case the helices preferentially packed in parallel. The two crystallographically distinct sodium ions in $\mathbf{3 b}$ are in a pseudooctahedral environment, each capped by a one water and one diethyl ether. Both sodium ions in $\mathbf{8}$ are only coordinated by the two borates and one THF. On careful examination of the structure of $\mathbf{8}$, however, it was apparent that the two crystallographically distinct sodium atoms are not in identical<smiles>[X]c1cccc(-c2cccc([X])c2O[PH]2(O)Oc3c([X])cccc3-c3cccc([Y])c3O2)c1O</smiles>

Fig. 14 The specification of the CSD database mining criteria. Variables specified: $\mathrm{X}_{1-5}$. A general search for "any $\mathrm{X}_{5}$ ", any bond in the aromatic rings, and allowing any substituents gave a total of 120 hits; these were examined in more detail by hand to find relevant species.
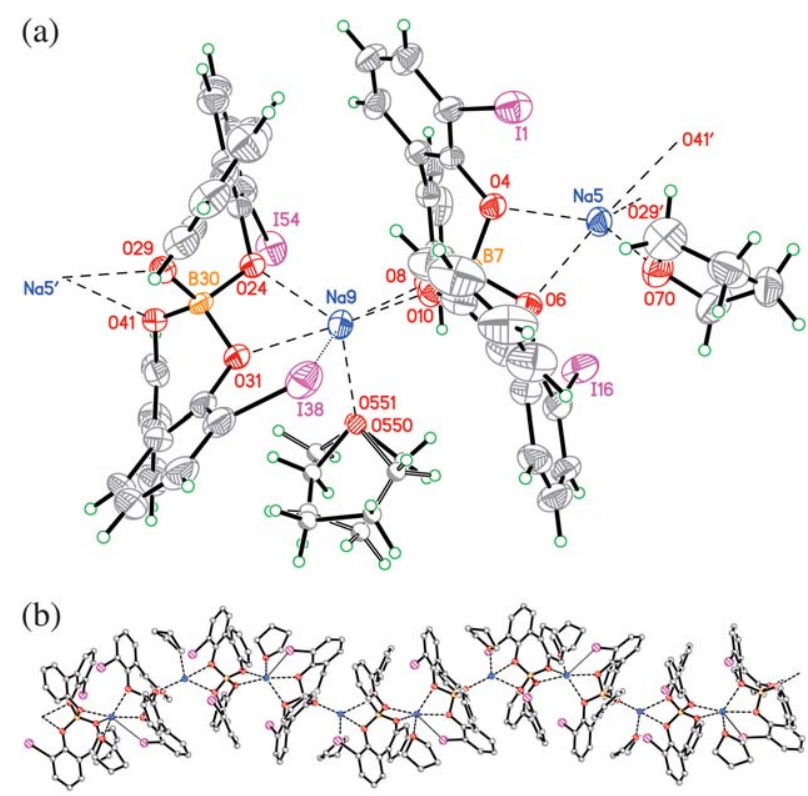

Fig. 15 Thermal ellipsoid plot of 8 showing (a) the bis-3,3'-diiodo-2,2'biphenol borate, with (b) the extended chain (hydrogen atoms and disordered components omitted for clarity). Selected bond lengths $[\AA]$ : B7-O4: 1.382(8), B7-O6: 1.476(9), B7-O8: 1.470(10), B7-O10: 1.444(10), Na5-O29': 2.313(5), Na5-O41': 2.388(6), Na5-B30': 2.968(8), Na5-O6 2.336(5), Na5-O70': 2.279(6), B30-O24: 1.506(9), O29-B30: 1.446(9), B30-O31: 1.465(8), B30-O41: 1.462(9), Na9-O8: 2.307(9), Na9-O10': 2.424(6), Na9-O24: 2.395(5), Na9-O31: 2.345(6), Na9ㄱI38: 3.483(3), Na9-O550: 2.516(11). Selected angles [ ${ }^{\circ}$ ]: O4-B7-O6: 99.7(6), O6-B7O8: 112.9(6), O4-B7-O8: 113.0(6), O6-B7-O10: 113.9(6), O4-B7-O10: 116.9(6), O8-B7-O10: 101.0(6), O24-B30-O29: 113.3(5), O24-B30-O31: 100.1(5), O24-B30-O41: 113.1(5), O29-B30-O31: 114.8(6), O29-B30O41: 102.5(5), O31-B30-O41: 113.5(5). Selected dihedral angles [ ${ }^{\circ}$ ]: $\mathrm{C} 60$ C65-C66-C3: 45.0(10), C11-C12-C13-C14: 41.0(13), C25-C26-C27C28: -46.2(10), C32-C33-C39-C40: -43.2(12).

environments. One of the borates is twisted by lengthening one of the $\mathrm{Na} \cdots \mathrm{I}$ distances and shortening the other bringing it within the sum of the van der Waals radii (4.496(3) and 3.483(3) $\AA$ respectively, compared with 4.035(3) and 4.081(3) A for Na5). Thus, for one sodium ion, the coordinative unsaturation is partially satisfied by a weak halogen bond with one of the iodines. This is not the case for the other and the asymmetric nature of this interaction together with the asymmetry of the mono-iodo biphenyl causes the chain to twist and form a helix.

\section{Conclusions}

This study demonstrated the preference of bis-BINOL and bisbiphenol borate frameworks to form homochiral entities in the solid state. Where an uncoordinated cation is present, this is likely to favour the formation of a homochiral species due to favourable interactions with the oxygens of the anion. However, even when this effect is removed, the homochiral species is still preferred suggesting that, to a certain extent, energetic penalties associated with the homochiral diastereomer appear to be overcome by solvation, conformational changes and/or crystal packing effects. The recent report by Straub et al. ${ }^{10}$ of a heterochiral aluminate suggests that a heterochiral borate may be accessible with sufficient steric bulk at the 3,3'-position. 
However, it is unclear what influence the increased radius of the aluminium may have had in the preparation of this material.

\section{Experimental section}

\section{Representative synthetic procedure; sodium $( \pm)-1,1^{\prime}-$ binaphthalene-2,2' -diol borate ${ }^{15}$}

$( \pm)$-1, $1^{\prime}$-Binaphthalene-2,2'-diol $(1.00 \mathrm{~g}, \quad 3.5 \mathrm{mmol})$ and $\mathrm{NaB}(\mathrm{OMe})_{4}(0.29 \mathrm{~g}, 1.8 \mathrm{mmol})$ were dissolved in $30 \mathrm{ml} \mathrm{THF}$ and heated to reflux for $10 \mathrm{~h}$. The suspension was then allowed to cool down to $40{ }^{\circ} \mathrm{C}$ and treated with $\mathrm{B}(\mathrm{OMe})_{3}(0.24 \mathrm{~g}, 0.32 \mathrm{ml}$, $2.27 \mathrm{mmol})$. Upon cooling, a white precipitate spontaneously formed. The resulting suspension was stirred at $40{ }^{\circ} \mathrm{C}$ for $1 \mathrm{~h}$ and then refluxed for $3 \mathrm{~h}$. The suspension was subsequently allowed to cool down to $20{ }^{\circ} \mathrm{C}$ and the title compound allowed to crystallise over $5 \mathrm{~h}$. The thus obtained white precipitate was filtered off and washed with $20 \mathrm{ml} \mathrm{THF}$, followed by $2 \times 20 \mathrm{ml} \mathrm{Et}_{2} \mathrm{O}$ and $20 \mathrm{ml}$ pentane. Drying in vacuo yielded the title compound as a white crystalline solid $(1.01 \mathrm{~g}, 1.75 \mathrm{mmol}, 96 \%) .{ }^{16} \mathrm{mp}>300{ }^{\circ} \mathrm{C}$; IR (neat) 3059, 1618, 1591, 1506, 1464, 1429, 1367, 1333, 1265, $1246,1070,985,949,908 \mathrm{~cm}^{-1} ; \delta_{\mathrm{H}}\left(500 \mathrm{MHz}, \mathrm{DMSO}-\mathrm{d}_{6}\right): 7.13$ $\left(1 \mathrm{H}, \mathrm{d}, J_{8,7}=8 \mathrm{~Hz}, \mathrm{H}-8\right), 7.16(1 \mathrm{H}, \mathrm{t}, J=8 \mathrm{~Hz}, \mathrm{H}-7), 7.29(1 \mathrm{H}, \mathrm{t}$, $J=7 \mathrm{~Hz}, \mathrm{H}-6), 7.33\left(1 \mathrm{H}, \mathrm{d}, J_{3,4}=9 \mathrm{~Hz}, \mathrm{H}-3\right), 7.93\left(1 \mathrm{H}, \mathrm{d}, J_{5,6}=\right.$ $9 \mathrm{~Hz}, \mathrm{H}-5), 7.97\left(1 \mathrm{H}, \mathrm{d}, J_{4,3}=9 \mathrm{~Hz}, \mathrm{H}-4\right) ; \delta_{\mathrm{C}}(126 \mathrm{MHz}$, DMSO$\left.\mathrm{d}_{6}\right)$ : 121.8 (C-1), 122.3 (C-6), 124.5 (C-3), 124.8 (C-7), 125.8 (C-8), 128.0 (C-5), 128.1 (C-4), 128.9 (C-9), 132.8 (C-10), 156.1 (C-2); $\delta_{\mathrm{B}}$ (160 MHz, DMSO-d ( $_{6}$ ): $9.2 \mathrm{ppm} ; \mathrm{m} / z$ (ESI) calc. for $\left[\mathrm{C}_{40} \mathrm{H}_{24} \mathrm{BO}_{4}\right]^{-}$579.1773, found $579.1791 \%$.

\section{Crystallisation protocols applied}

Two distinct crystallisation procedures were employed for the sodium salts and the crown ether complexes, respectively. Single crystals of all sodium salts were grown by preparing refluxing THF solutions and allowing them to cool down overnight in an oil bath. This had to be followed by slow evaporation of solvent over a week for the compounds $\mathbf{3 , 5}$ and $\mathbf{7}$. The crown complexes yielded single crystals by slow evaporation of a $1: 1$ solvent mixture of $\mathrm{CH}_{2} \mathrm{Cl}_{2}$ and $\mathrm{C}_{6} \mathrm{~F}_{6}$.

\section{Crystallographic details}

In each case, a typical crystal was mounted using the oil drop technique, in perfluoropolyether oil at 150(2) K (except 3a, see below) with a Cryostream $\mathrm{N}_{2}$ open-flow cooling device. ${ }^{17}$ Single crystal X-ray diffraction data were collected using graphite monochromated Mo-K $\alpha$ radiation $(\lambda=0.71073 \AA)$ using a Nonius KappaCCD diffractometer. Series of $\omega$-scans were generally performed to provide sufficient data in each case to a maximum resolution of $0.77 \AA$. Data collection and cell refinement were carried out using DENZO-SMN. ${ }^{18}$ Intensity data were processed and corrected for absorption effects by the multi-scan method, based on multiple scans of identical and Laue equivalent reflections using SCALEPACK (within DENZO-SMN). Structure solution was carried out with direct methods using the programs SIR $92^{19}$ or SuperFlip ${ }^{20}$ within the CRYSTALS software suite. ${ }^{21}$ In general, coordinates and anisotropic displacement parameters of all non-hydrogen atoms were refined separately (except where this was not possible due to the presence of disorder which is discussed in the CIF). Hydrogen atoms were generally visible in the difference map and were treated in the usual manner. ${ }^{22}$ In the case of compound $\mathbf{3 a}, \mathbf{3 b}$, and 4, the Fourier difference map indicated the presence of diffuse electron density believed to be disordered solvent. PLATON/SQUEEZE ${ }^{23}$ was used leaving a void from which the electron density was removed. The discrete Fourier transforms of the void regions were treated as contributions to the A and B parts of the calculated structure factors. The data for 3a were collected at $250 \mathrm{~K}$ because the compound appeared to undergo a destructive phase transition below this temperature and was unstable to loss of THF above it. Consequently there is a considerable degree of thermal motion. Efforts were made to refine the structure with a multi-part model, but the refinement was unstable. 3D Fourier maps ${ }^{24}$ were examined and it was apparent that each atom has a single locus, so a single component model was used with prolate thermal ellipsoids and 1,2 and 1,3 vibration/thermal similarity restraints for the THF molecules in order to maintain sensible parameters. Similarly, the data for $\mathbf{4}$ are particularly poor although the connectivity is in little doubt, so the structure is included herein for completion only and the derived parameters are not discussed. Cell parameters, agreement factors, etc. are given in the footnotef; refinement details are also available in the ESI $\uparrow$.

\$ Single crystal X-ray diffraction data for 3a (CCDC 796350): $\mathrm{C}_{36} \mathrm{H}_{40} \mathrm{BNaO}_{7},{ }^{28} M_{\mathrm{r}}=618.51$, triclinic $(P \overline{1}), a=9.1073(2) \AA, b=$ 11.9788(3) $\AA, c=18.7883(5) \AA, \alpha=94.9284(9)^{\circ}, \beta=100.7991(9)^{\circ}$, $\gamma=105.1909(12)^{\circ}, V=1923.24(8) \AA^{3}, Z=2, \mu=0.082 \mathrm{~mm}^{-1}, D_{\text {calc }}$, $1.068 \mathrm{Mg} \mathrm{m}^{-3}, T=250(2) \mathrm{K}, 5981$ independent reflections $[R$ (int) $=$ $0.046], R_{1}=0.0854, \mathrm{w} R_{2}=0.0934[I>2 \sigma(I)]$. Single crystal $X$-ray diffraction data for $\mathbf{3 b}(\mathrm{CCDC} 796351): \mathrm{C}_{28} \mathrm{H}_{28} \mathrm{BNaO}_{6},{ }^{28} M_{\mathrm{r}}=494.33$, orthorhombic (Pccn), $a=22.3739(2) \mathrm{A}, b=24.2103(2) \AA, c=$ 18.9483(1) $\AA, V=10263.89(14) \AA^{3}, Z=16, \mu=0.102 \mathrm{~mm}^{-1}, D_{\text {calc }}=$ $1.280 \mathrm{Mg} \mathrm{m}^{-3}, T=150(2) \mathrm{K}, 11685$ independent reflections $[R$ (int) $=$ $0.062], R_{1}=0.0644, \mathrm{w} R_{2}=0.0679[I>2 \sigma(I)]$. Single crystal $X$-ray diffraction data for 3c (CCDC 796352): $\mathrm{C}_{12} \mathrm{H}_{26} \mathrm{NaO}_{7}, \mathrm{C}_{24} \mathrm{H}_{16} \mathrm{BO}_{4}$, $M_{\mathrm{r}}=684.52$, monoclinic $\left(P 2_{1} / n\right), a=11.9831(2) \AA, b=21.9931(5) \AA$, $c=13.4659(3) \AA, \beta=106.0392(10)^{\circ}, V=3410.73(12) \AA^{3}, Z=4, \mu=$ $0.108 \mathrm{~mm}^{-1}, D_{\text {calc }}=1.333 \mathrm{Mg} \mathrm{m}^{-3}, T=150(2) \mathrm{K}, 7686$ independent reflections $[R($ int $)=0.063], R_{1}=0.0525, \mathrm{w} R_{2}=0.1093[I>2 \sigma(I)]$. Single crystal $X$-ray diffraction data for 4 (CCDC 796353): $\mathrm{C}_{56} \mathrm{H}_{56} \mathrm{BNaO}_{7},{ }^{28} M_{\mathrm{r}}=874.86$, triclinic $(P \overline{1}), a=9.0212(5) \AA, b=$ 16.6116(9) $\AA, c=18.1651(10) \AA, \alpha=71.295(2)^{\circ}, \beta=88.316(2)^{\circ}, \gamma=$ 79.317(2) $, V=2532.4(2) \AA^{3}, Z=2, \mu=0.081 \mathrm{~mm}^{-1}, D_{\text {calc }}=1.147$ $\mathrm{Mg} \mathrm{m}^{-3}, T=225(2) \mathrm{K}, 9955$ independent reflections [ $R($ int $)=0.123$ ], $R_{1}=0.1100, \mathrm{w} R_{2}=0.2867[I>2 \sigma(I)]$. Single crystal $X$-ray diffraction data for 5 (CCDC 796354): $\mathrm{C}_{52} \mathrm{H}_{46} \mathrm{BI}_{4} \mathrm{NaO}_{8}, M_{\mathrm{r}}=1340.35$, monoclinic $\left(P 2_{1} / c\right), a=14.1036(2) \mathrm{A}, b=22.2147(3) \mathrm{A}, c=16.2473(2) \mathrm{A}, \beta=$ 104.8169(7) $, V=4921.13(12) \AA^{3}, Z=4, \mu=2.595 \mathrm{~mm}^{-1}, D_{\text {calc }}=$ $1.809 \mathrm{Mg} \mathrm{m}^{-3}, T=150(2) \mathrm{K}, 11210$ independent reflections $[R$ (int) $=$ $0.060], R_{1}=0.0350, \mathrm{w} R_{2}=0.0709[I>2 \sigma(I)]$. Single crystal $X$-ray diffraction data for 6 (CCDC 796355): $\mathrm{C}_{72} \mathrm{H}_{64} \mathrm{BNaO}_{8}, M_{\mathrm{r}}=1340.35$, monoclinic (C2/c), $a=25.5708(2) \AA, b=9.8286(1) \AA, c=23.5937(2)$ $\AA, \beta=111.3071(4)^{\circ}, V=5524.37(9) \AA^{3}, Z=4, \mu=0.091 \mathrm{~mm}^{-1}, D_{\text {calc }}$ $=1.312 \mathrm{Mg} \mathrm{m}^{-3}, T=150(2) \mathrm{K}, 6298$ independent reflections $[R$ (int) $=$ 0.047], $R_{1}=0.0484, \mathrm{w} R_{2}=0.1277[I>2 \sigma(I)]$. Single crystal $X$-ray diffraction data for 7 (CCDC 796356): $\mathrm{C}_{24} \mathrm{H}_{12} \mathrm{BI}_{4} \mathrm{O}_{4}, \mathrm{C}_{12} \mathrm{H}_{24} \mathrm{NaO}_{6}, M_{\mathrm{r}}$ $=1340.35$, monoclinic $\left(P 2_{1} / n\right), a=14.7887(2) \AA, b=14.5866(2) \AA$, $c=18.4806(3) \AA, \beta=92.9658(5)^{\circ}, V=3981.24(10) \AA^{3}, Z=4, \mu=$ $3.195 \mathrm{~mm}^{-1}, D_{\text {calc }}=1.952 \mathrm{Mg} \mathrm{m}^{-3}, T=150(2) \mathrm{K}, 9426$ independent reflections $[R($ int $)=0.088], R_{1}=0.0381, \mathrm{w} R_{2}=0.0728[I>2 \sigma(I)]$. Single crystal $X$-ray diffraction data for 8 (CCDC 796357): $\mathrm{C}_{28} \mathrm{H}_{22} \mathrm{BI}_{2} \mathrm{NaO}_{4}, M_{\mathrm{r}}=726.09$, monoclinic $\left(P 2_{1}\right), a=11.3796(2) \AA, b=$ $21.7120(4) \AA, c=12.3028(2) \AA, \beta=116.3450(8)^{\circ}, V=2723.99(8) \AA^{3}$, $Z=4, \mu=2.361 \mathrm{~mm}^{-1}, D_{\text {calc }}=1.770 \mathrm{Mg} \mathrm{m}^{-3}, T=150(2) \mathrm{K}, 11234$ independent reflections $[R($ int $)=0.064], R_{1}=0.0470, \mathrm{w} R_{2}=0.0977[I$ $>2 \sigma(I)]$, Flack $^{29} x=0.00(2)$. 


\section{Computational details}

All computations were performed on the isolated anions ${ }^{25}$ using the hybrid Becke functional (B3), for electron exchange and the correlation functional of Lee, Yang and Parr (LYP), as implemented in the Gaussian 09 software package. ${ }^{26}$ An initial set of geometry optimisations was performed using the SDD basis set for iodine and 6-31G(d) otherwise (BS1). Frequency calculations were undertaken to confirm the nature of the stationary points, yielding one imaginary frequency for the transition state and zero for the minima. ${ }^{27}$ The structures were subsequently reoptimised employing the SDD basis set for iodine and 6-31 + G-(d) for all other atoms (BS2). ${ }^{27}$ Geometry optimisations were performed without any symmetry constraints $\left(C_{1}\right.$ symmetry). Zero-point corrections obtained from the frequency calculations at the B3LYP/BS1 level of theory were applied to the energies obtained in geometry optimisations at the B3LYP/BS2 level of theory. Zero-point energies from $6-31 \mathrm{G}^{*}$ were used throughout.

\section{Acknowledgements}

J.M.B. thanks the Leverhulme Trust for a Fellowship. J.A.R. acknowledges the 'Verband der Chemischen Industrie' for a doctoral scholarship. We thank the Oxford Supercomputing Service for access to facilities.

\section{Notes and references}

1 (a) J. Lacour and R. Frantz, Org. Biomol. Chem., 2005, 3, 15; (b) M. Terada, Chem. Commun., 2008, 4097.

2 M. Oki, Top. Stereochem., 1983, 14, 4193.

3 (a) T. Akiyama, J. Itoh, K. Yokota and K. Fuchibe, Angew. Chem. Int. Ed., 2004, 43, 1566; (b) S. Mayer and B. List, Angew. Chem., Int. Ed., 2006, 45, 4193; (c) G. L. Hamilton, E. J. Kang, M. Mba and F. D. Toste, Science, 2007, 317, 496; (d) M. Terada, K. Soga and N. Momiyama, Angew. Chem., Int. Ed., 2008, 47, 4122.

4 (a) M. Periasamy, C. R. Ramanathan and N. S. Kumar, Tetrahedron: Asymmetry, 1999, 10, 2307; (b) M. Periasamy, N. S. Kumar, S. Sivakumar, V. D. Rao, C. R. Ramanathan and L. Venkatraman, J. Org. Chem., 2001, 66, 3828.

5 (a) D. B. Llewellyn, D. Adamson and B. A. Arndtsen, Org. Lett., 2000, 2, 4165; (b) C. Carter, S. Fletcher and A. Nelson, Tetrahedron: Asymmetry, 2003, 14, 1995; (c) D. Chen, B. Sundararaju, R. Krause, J. Klankermayer, P. Dixneuf and W. Leitner, ChemCatChem, 2010, 2, 55.

6 (a) T. Tu, T. Maris and J. D. Wuest, J. Org. Chem., 2008, 73, 5255; (b) E. Voisin, T. Maris and J. D. Wuest, Cryst. Growth Des., 2008, 8, 308

7 J. A. Raskatov; A. L. Thompson; T. D. W. Claridge; J. M. Brown, in preparation; J. A. Raskatov, D.Phil thesis, Oxford, 2009.

8 See ESI $\dagger$ for full details.

9 Mass-spectrometric pseudoracemate experiments using $(R)$-BINOL and $(S)$-dideutero-BINOL were attempted to gain insight into the solution behaviour of the reaction mixture of 2 , but did not yield conclusive results.

10 B. F. Straub, M. Wrede, K. Schmid and F. Rominger, Eur. J. Inorg. Chem., 2010, 1907.

11 J. Knizek, H. Noth and M. Warchhold, Z. Naturforsch., B: J. Chem. Sci., 2006, 61, 1079.

12 S. Matsunaga, J. Das, J. Roels, E. M. Vogl, N. Yamamoto, T. Iida, K. Yamaguchi and M. Shibasaki, J. Am. Chem. Soc., 2000, 122, 2252.
13 Sohnke space groups are often incorrectly referred to as "chiral" space groups.

14 A racemic material that crystallises in a Sohnke space group with both hands in the asymmetric unit such that it fails to make use of the inversion symmetry available is known as a chiral racemate. Examples are given in: J. Jacques, A. Collet and S. H. Wilen, Enantiomers, Racemates and Resolutions, Krieger Publishing Company, Malabar, 1981; R. G. Kostyanovsky, V. R. Kostyanovsky and G. K. Kadorkina, Mendeleev Commun., 2009, 19, 17; L. Curry, M. S. Hallside, L. H. Powell, S. J. Sprague and J. W. Burton, Tetrahedron, 2009, 65, 10882; L. Fabian and C. P. Brock, Acta Crystallogr., Sect. B: Struct. Sci., 2010, 66, 94.

15 Full details of preparation and characterisation of borates will be published elsewhere ${ }^{7}$.

16 In cases when spontaneous crystallisation did not occur, the corresponding compound was precipitated with $\mathrm{Et}_{2} \mathrm{O}$.

17 J. Cosier and A. M. Glazer, J. Appl. Crystallogr., 1986, 19, 105.

18 Z. Otwinowski and W. Minor, Methods in Enzymology, ed. C. W. Carter, Jr and R. M. Sweet, Academic Press, New York, 1997, vol. 276, pp. 307-326.

19 A. Altomare, G. Cascarano, C. Giacovazzo and A. Guagliardi, J. Appl. Crystallogr., 1994, 27, 1045.

20 L. Palatinus and G. Chapuis, J. Appl. Crystallogr., 2007, 40, 786.

21 P. W. Betteridge, J. R. Carruthers, R. I. Cooper, K. Prout and D. J. Watkin, J. Appl. Crystallogr., 2003, 36, 1487.

22 R. I. Cooper, A. L. Thompson and D. J. Watkin, J. Appl. Crystallogr., 2010, 43, 1100.

23 A. L. Spek, J. Appl. Crystallogr., 2003, 36, 7; P. Vandersluis and A. L. Spek, Acta Crystallogr., Sect. A: Found. Crystallogr., 1990, 46, 194; A. L. Spek, PLATON, A Multipurpose Crystallographic Tool, Utrecht, The Netherlands, 1998.

24 J. Rohlicek and M. Husak, J. Appl. Crystallogr., 2007, 40, 600.

25 The computation was carried out with isolated anions as taking the Na-counterion into account would require the explicit consideration of THF solvent molecules, which makes the endeavour computationally elaborate and is exacerbated by the number and position of poorly defined, dynamic THF molecules.

26 M. J. Frisch, G. W. Trucks, H. B. Schlegel, G. E. Scuseria, M. A. Robb, J. R. Cheeseman, G. Scalmani, V. Barone, B. Mennucci, G. A. Petersson, H. Nakatsuji, M. Caricato, X. Li, H. P. Hratchian, A. F. Izmaylov, J. Bloino, G. Zheng, J. L. Sonnenberg, M. Hada, M. Ehara, K. Toyota, R. Fukuda, J. Hasegawa, M. Ishida, T. Nakajima, Y. Honda, O. Kitao, H. Nakai, T. Vreven, J. A. Montgomery, Jr, J. E. Peralta, F. Ogliaro, M. Bearpark, J. J. Heyd, E. Brothers, K. N. Kudin, V. N. Staroverov, R. Kobayashi, J. Normand, K. Raghavachari, A. Rendell, J. C. Burant, S. S. Iyengar, J. Tomasi, M. Cossi, N. Rega, J. M. Millam, M. Klene, J. E. Knox, J. B. Cross, V. Bakken, C. Adamo, J. Jaramillo, R. Gomperts, R. E. Stratmann, O. Yazyev, A. J. Austin, R. Cammi, C. Pomelli, J. W. Ochterski, R. L. Martin, K. Morokuma, V. G. Zakrzewski, G. A. Voth, P. Salvador, J. J. Dannenberg, S. Dapprich, A. D. Daniels, O. Farkas, J. B. Foresman, J. V. Ortiz, J. Cioslowski and D. J. Fox, Gaussian 09, Revision A.02, Gaussian, Inc., Wallingford CT, 2009.

27 (a) D. Andrae, U. Haeussermann, M. Dolg, H. Stoll and H. Preuss, Theor. Chim. Acta, 1990, 77, 123; (b) R. Ditchfield, W. J. Hehre and J. A. Pople, J. Chem. Phys., 1971, 54, 724; (c) W. J. Hehre, R. Ditchfield and J. A. Pople, J. Chem. Phys., 1972, 56, 2257; (d) P. C. Hariharan and J. A. Pople, Theor. Chim. Acta, 1973, 28, 213; (e) P. C. Hariharan and J. A. Pople, Mol. Phys., 1974, 27, 209; (f) M. S. Gordon, Chem. Phys. Lett., 1980, 76, 163.

28 Excluding an unknown amount of disordered solvent that has been removed using PLATON/SQUEEZE ${ }^{23}$

29 H. D. Flack, Acta Crystallogr., Sect. A: Found. Crystallogr., 1983, 39, 876-881. 